\title{
Memória e Identidade: um estudo das trabalhadoras do Banco do Estado do Rio Grande do Sul - 1943-45
}

Aurea Tomatis Petersen ${ }^{*}$

\begin{abstract}
Resumo: Este artigo discute brevemente a questão da memória e da identidade e detémse na exposição de pesquisa realizada no final da década de 1990 que utilizou história oral e apoiou-se na memória das primeiras trabalhadoras que ingressaram no Banco do Estado do Rio Grande do Sul entre 1943-45, procurando construir a identidade do grupo em estudo.
\end{abstract}

Abstract: This article briefly argues the question of the memory and the identity and is lingered in the exposition of research carried through in the end of the decade of 1990 using verbal history, and it was supported in the memory of the first workers who had entered the BANRISUL between 1943-45, looking for to construct their identity of the group in study.

Palavras-chave: Memória. Identidade. Bancárias.

Key words: Memory. Identity. Workers of banks.

\section{Memória e Identidade: revisando alguns conceitos}

Disse Pierre Nora (1978) que a palavra memória é vaga e ambígua, mas que sua utilização estratégica pode ser fecunda para a renovação da historiografia. Para Nora "a memória coletiva é a recordação ou o conjunto de recordações, conscientes ou não, de uma experiência vivida e/ou mitificada por uma comunidade viva de cuja identidade faz parte integrante o sentimento do passado" (p. 451).

Foi pensando nas afirmações de Nora que, para realizar-se o estudo relativo à inserção das primeiras trabalhadoras do Banco do Estado do Rio Grande do Sul (Banrisul), trabalhou-se com hisDoutora em História do Brasil; Professora da Faculdade de Filosofia e Ciências
Humanas da PUCRS. E-mail: aupeter@portoweb.com.br

Estudos Ibero-Americanos. PUCRS, v. XXXII, n. 1, p. 209-225, junho 2006 
tória oral buscando recuperar o material que fora guardado na memória dessas trabalhadoras.

Para uma maior compreensão do conceito de memória, recorreu-se à contribuição de dois autores - o filósofo francês Henri Bergson e o sociólogo, também francês, Maurice Halbwachs. O primeiro foi trabalhado de forma mais breve e o segundo um pouco mais detalhadamente. Em vários momentos, recorreu-se a observações e esclarecimentos feitos por estudiosas da memória que fundamentaram seus estudos na obra desses dois autores Cita-se Ecléia Bosi (1994) e Miriam Sepúlveda dos Santos (1998).

Com relação Henry Bergson, segundo Bosi (1994), o filósofo entendia que o passado conservava-se e atuava no presente, mas não de forma homogênea. Para Bergson, de um lado, nosso corpo guarda esquemas de comportamento de que se vale muitas vezes automaticamente na sua ação sobre as coisas. Isto seria o que ele denominou memória-hábito ou a memória dos mecanismos motores. De outro lado, ocorreriam as lembranças independentes de quaisquer hábitos: lembranças isoladas, singulares, que constituiriam autênticas ressurreições do passado.

Comentando as duas formas de memória, identificadas por Bergson, Bosi (1994) afirma que a memória-hábito é adquirida pelo esforço da atenção e pela repetição de gestos e palavras, podendo essa memória ser considerada como parte de nosso processo de adestramento. Por sua vez, a lembrança pura traz a tona um momento único, singular, não repetido, irreversível. Para Bergson a matéria dessas memórias reside no inconsciente de cada um de nós. Através da memória, o passado sobrevive, como diz Bosi, "quer chamado pelo presente sob as formas de lembrança, quer em si mesmo, em estado inconsciente" (p. 53).

No que respeita a Maurice de Halbwachs, pode-se dizer que o sociólogo distinguiu dois tipos de memória, a "autobiográfica", pessoal e vivida, que necessariamente sofre influência do meio social, sendo sempre filtrada pelo presente, e a "memória histórica", que é passada para o indivíduo pela coletividade e que se refere a coisas e processos do passado que ele não vivenciou, mas que, a partir desse processo, passam a fazer parte da sua história.

Halbwachs priorizou, em seus estudos, a análise do que ele denominou de "quadros sociais da memória" ou das "representações coletivas", tema desenvolvido em trabalho escrito em 1925, intitulado Les cadres sociaux de la mémoire. Nessa obra, o autor procurou estabelecer o que pode ser considerado como os princípios fundamentais de uma teoria sobre memória. 
A questão central trabalhada por Halbwachs (1925) é: quaisquer que sejam as lembranças do passado que possamos ter - por mais que pareçam resultado de sentimentos, pensamentos e experiências exclusivamente individuais -, só podem existir a partir dos "quadros sociais da memória".

Entende Halbwachs que nós construímos nossas memórias como membros de determinados grupos sociais e que para tal utilizamos as convenções sociais presentes na sociedade em que vivemos. Como salienta Santos (1998), com base no autor, indivíduos não se lembram por eles mesmos, isto é, para lembrarem, necessitam da lembrança de outros indivíduos, de modo a confirmar ou negar suas lembranças, as quais estão localizadas em algum lugar específico no tempo e no espaço.

Assim, para Halbwachs quando lembramos de um evento do passado, o fazemos por meio da reconstrução de uma série de imagens fragmentadas e de um conhecimento acumulado a partir de experiências já vivenciadas.

No momento exato em que se expressa o passado sob a forma de imagem reconstruída, dá-se ao passado uma localização específica no tempo e no espaço. Logo, como a imagem lembrada é sempre uma criação do presente, há sempre uma distância entre a imagem construída sobre o passado - em gestos, pensamentos ou ações - e o passado, embora este último não esteja ausente da imagem do presente.

Para o autor, a memória individual não é possível sem determinados instrumentos, que se situam fora do indivíduo, como as palavras e idéias que não são inventados pelos indivíduos, mas recolhidos do meio social em que vivem. Sobre esse aspecto Bosi (1994) afirma que as relações não ficam adstritas ao mundo da pessoa, mas constroem-se na realidade interpessoal, sofrendo influência das mais variadas instituições sociais de que o indivíduo participa, tais como a classe social, a família, a escola, a igreja, a profissão.

As colocações de Halbwachs podem ser resumidas no que afirma Bosi (1994, p. 55). Conforme autora, "lembrar não é reviver, mas refazer, reconstruir, repensar, com imagens e idéias de hoje, as experiências do passado". Para a autora, a lembrança é uma imagem construída pelos materiais que estão agora à nossa disposição, no conjunto de representações que povoam nossa consciência atual. $\mathrm{O}$ fato de lembrar o passado no presente exclui a identidade entre as imagens de um e outro e propõe a sua diferença em termos de um ponto de vista. 
Reforçando as idéias de Bosi, é possível recorrer a Agnes Heller (1993, p. 53), que considera toda recordação passada "uma interpretação ou uma reconstrução do passado". Segundo Heller, "as experiências que tivemos, nossos interesses, sinceridade e insinceridade, tudo isso modifica aquilo que reconstruímos, o modo pelo qual o fazemos e o tipo de significação que atribuímos ao passado reconstruído".

\section{Memória e Identidade: reconstruindo a trajetória das primeiras trabalhadoras do Banco do Estado do Rio Grande do Sul ${ }^{1}$}

Com base no que foi apresentado até aqui, pode-se concluir que a memória tem um papel fundamental na construção da identidade de um grupo social, especialmente se esse grupo se situa entre aqueles que Michelle Perrot (1992) denominou de "os excluídos da história", entre os quais se encontram as mulheres, objeto deste estudo.

A quase inexistência de registros acerca do passado das mulheres constitui-se em um dos grandes problemas enfrentados pelos(as) historiadores(as) que se dedicam a esse tema. Como afirmaram Michelle Perrot e Georges Duby (1990), "os tênues vestígios ou os indícios da presença feminina, considerados sem importância, geralmente foram desprezados e apagaram-se no tempo", dificultando, quando não impedindo, a reconstituição da trajetória das mulheres. "No teatro da memória, as mulheres são leves sombras, ocupando pouco espaço nas estantes dos arquivos públicos" (p. 11).

Um agravante dessa situação é que pesquisadores e pesquisadoras que estudam o assunto encontram, por vezes, representações sobre o feminino baseadas em discursos masculinos que, na maioria das vezes, descrevem as mulheres tal como eram pensadas ou vistas por uma cultura marcadamente patriarcal. Dessa forma, além dos registros relativos à história delas serem muito raros, os poucos que são encontrados, muitas vezes, veiculam uma falsa imagem das mulheres.

Por essa razão, ao procurar reconstituir a identidade das primeiras trabalhadoras do Banco do Estado do Rio Grande do Sul,

1 Essa parte do artigo está baseada no capítulo IV de minha Tese de Doutorado, intitulada Trabalhando no Banco: trajetória das mulheres gaúchas desde 1920, defendida em 1999 no Programa de Pós-graduação em História da PUCRS. A tese, com informações bem mais detalhadas, encontra-se na Biblioteca da PUCRS. 
após levantamento em registros escritos, foi necessário buscar informações complementares, trabalhando a memória das mulheres do referido banco por meio da História Oral.

Apesar de utilizar fundamentalmente a evidência oral, no estudo realizado, recorreu-se, sempre que possível, a informações contidas nas fichas funcionais das depoentes e em outros documentos localizados no acervo do Museu do Banrisul. O recurso a essas outras fontes teve por objetivo confirmar a consistência interna do material obtido através dos depoimentos e, sempre que possível, completar os espaços deixados em branco pelo esquecimento.

Mesmo julgando da maior relevância a utilização da fonte oral para a reconstituição da história das mulheres, teve-se sempre bem claro, considerando-se especialmente a contribuição de Halbwachs, que as trabalhadoras que contaram as suas histórias, o fizeram com as imagens e idéias de hoje, do seu presente. Elas ingressaram no banco em um tempo que já está distante e o que recordam desse tempo e lugar aparece a elas a partir de estruturas e configurações sociais do presente. Elas olharam do seu presente para o seu passado e reconstituíram o seu tempo e o seu lugar com os materiais que têm hoje a sua disposição.

Ressalte-se que o trabalho com os depoimentos coletados, absolutamente, significa que se pretenda sugerir que as informações recolhidas entre as depoentes, permitam chegar à reconstituição da história do conjunto das trabalhadoras do Banco do Estado do Rio Grande do Sul e muito menos do setor bancário gaúcho. Os depoimentos reunidos permitem analisar a trajetória de um grupo de trabalhadoras, reconstituir o seu dia-a-dia e identificar suas atitudes e seus valores. Considera-se, todavia, que o material obtido fornece "indícios" importantes para a análise das relações de gênero no banco em estudo, assim como para a análise das relações de gênero em um sentido mais amplo.

A pesquisa realizada, utilizando história oral, propôs-se a responder a um conjunto de indagações: Que fatores, no início da década de 1940, teriam motivado a decisão de trabalhar de várias mulheres? Por que teriam escolhido um banco como local de trabalho, especialmente considerando que os bancos, à época, eram espaços de trabalho fundamentalmente masculinos? Qual teria sido a reação da família frente à escolha de jovens por esse local de trabalho? De que natureza seriam as relações que se estabeleceram entre homens e mulheres no espaço bancário? Os salários de homens e mulheres seriam iguais? As mulheres teriam as mesmas possibilidades que tinham os homens de ascensão funcional? Co- 
mo as trabalhadoras conseguiriam atender às obrigações decorrentes da profissão e dar conta das tarefas atribuídas às mulheres em casa? Quais seriam os principais valores e as principais atitudes das primeiras trabalhadoras do Banco do Estado do Rio Grande do Sul?

Procurando obter respostas a todas essas indagações, ouviuse oito mulheres das trinta e nove que ingressaram no Banco entre 1943 e 1945, tendo o cuidado para que fizessem parte do grupo trabalhadoras que ingressaram em Porto Alegre e em algumas cidades do interior (Pelotas, Cachoeira, Livramento). A partir do trabalho da memória dessas mulheres, foi possível, pouco a pouco, reconstituir a identidade do grupo.

É interessante relatar que as mulheres que foram ouvidas não consideravam que tivessem desempenhado um papel relevante ao longo de sua trajetória no banco. Geralmente, modestas, elas começavam afirmando que não tinham uma história a contar, pois suas vidas não tinham sido importantes... Todavia, quando começavam a falar uma lembrança chamava outra. Acabaram contando muito, pois, na verdade, tinham muito a contar. Sua contribuição para a construção da identidade do grupo foi riquíssima. À medida que percebiam que seus relatos estavam reconstituindo a história do banco, tornavam-se cada vez mais colaborativas. Respondiam às indagações feitas, esclareciam dúvidas que surgiam ao longo do trabalho, traziam fotografias e documentos amarelados pelo tempo, indicavam telefones de outras possíveis depoentes, identificavam colegas em fotografias... Além disso, tiveram sempre toda a disponibilidade para esclarecer pelo telefone alguma dúvida surgida durante a análise de seus depoimentos.

Os dados coletados e analisados permitiram responder às indagações que motivaram a pesquisa e reconstituir a identidade das primeiras trabalhadoras do Banco do Estado do Rio Grande do Sul. Seguem-se abaixo os resultados a que se chegou.

\subsection{A decisão de trabalhar}

No que se refere à "decisão de trabalhar", foi possível constatar que as bancárias ouvidas pertenciam a famílias que desfrutavam de uma situação econômico-financeira relativamente confortável. Esse dado permite supor que seus salários não eram indispensáveis ou fundamentais na constituição do orçamento familiar. Assim sendo, a decisão de trabalhar, por elas tomada, pode, perfei- 
tamente, ter sido estimulada pela conjuntura política do início da década de 1940, que se tornara favorável ao trabalho feminino.

Acrescente-se que, em alguns dos depoimentos, ficou explícito o desejo das mulheres ouvidas de alcançar a independência financeira. Uma das depoentes foi muito clara: "eu queria a minha independência econômica, ... eu queria ser dona do que era meu". Outra disse que se formara professora, mas não fora nomeada porque as nomeações eram de dois em dois anos, e acrescentou: "Então fiquei desesperada. Eu queria trabalhar. Não que precisasse para manter a família, mas eu queria trabalhar".

Por outro lado, algumas das depoentes fizeram referência a que antes de ingressar no banco já haviam exercido alguma outra atividade remunerada, ajudando em casa comercial de parentes, trabalhando na oficina e no escritório do pai, dando aulas particulares, trabalhando em escritório. Além disso, uma das ouvidas aguardava que fosse aberto o concurso para o magistério, atividade para a qual estava habilitada, e outra esperava a nomeação para “o Imposto de Renda", em cujo concurso havia sido aprovada.

As mulheres ouvidas viveram a sua juventude quando novas idéias estavam emergindo, mas costumes, atitudes e valores de um tempo anterior ainda estavam muito presentes. Dessa forma, quando muito jovens e solteiras, elas, influenciadas pelo que o "seu tempo" colocava, desejavam ter um trabalho remunerado e independência financeira. Todavia, quando assumiram a condição de casadas, duas delas guiaram-se pelas influências do tempo anterior, pediram demissão no banco e foram para casa dedicar-se ao marido e aos filhos.

\subsection{A escolha do setor bancário}

Uma das indagações que motivou a realização desta pesquisa é o que teria levado várias jovens gaúchas a optarem por trabalhar no setor bancário. Indagava-se o que as teria estimulado decidirem ser bancárias, ao invés de optar por profissões que usualmente eram escolhidas pelas mulheres como, por exemplo, o magistério.

Os relatos analisados trouxeram uma informação interessante: não houve, propriamente, uma escolha do trabalho no setor bancário pelas depoentes. A maior parte delas afirmou que havia concluído o ginásio, o complementar ou o curso de auxiliar de comércio e desejava trabalhar, quando ficou sabendo, por parente ou amigo, que haveria seleção para o Banco do Estado do Rio Grande do Sul, resolvendo inscrever-se. 
Duas das depoentes chegaram a sugerir que o ingresso na carreira foi acidental. Outras disseram que, como não estavam trabalhando, resolveram inscrever-se no concurso, passaram e gostaram do trabalho e do ambiente que encontraram no banco. Uma delas disse que trabalhar em banco dava status, principalmente no Banco do Estado do Rio Grande do Sul.

Apenas duas das entrevistadas disseram ter escolhido a profissão de bancária. Uma delas contou que "desde menina" escolhera a profissão. Disse que morava no interior e via o trabalho vivido pelas professoras quando se deslocavam para cidades distantes. Isso a fez decidir jamais dedicar-se a tal profissão.

Os depoimentos das outras bancárias ouvidas evidenciam que, apesar de não ter, propriamente, havido uma escolha de profissão, elas sentiram-se bem no banco e, por esse motivo, permaneceram trabalhando. As duas que pediram demissão o fizeram porque tal procedimento ainda era comum entre as mulheres que contraíam matrimônio.

Deve ser ressaltado que várias das depoentes justificaram, senão o seu ingresso, a sua permanência no banco, referindo-se ao salário e afirmando que este era elevado. Também foram feitas comparações com os salários de outras profissões, como o magistério, tendo as bancárias afirmado que os seus salários eram bem mais altos do que os das professoras. Foi dito que no banco havia gratificações que tornavam maiores os ganhos anuais. Houve referência a que a profissão de bancária "era garantida, pois haviam feito concurso" e que era uma "profissão de futuro".

Além disso, a jornada de trabalho das bancárias era de seis horas, diferentemente de comerciárias, funcionárias públicas ou funcionárias de escritórios, que trabalhavam oito horas diárias. Sem a menor dúvida, a possibilidade de tempo parcial foi fator importante na escolha desse tipo de trabalho e na permanência no mesmo, principalmente no caso das casadas que continuaram trabalhando.

Deve ser ressaltado, que devido ao processo de socialização ao qual são submetidas, as mulheres, em geral, vêem o trabalho assalariado como subordinado e complementar, pois preferem seu vínculo com a família. Por essa razão, grande parte das mulheres procura atividades em tempo parcial. O trabalho no banco apresentava a possibilidade das mulheres atenderem a esse objetivo.

\subsection{A reação da família}


Considerando as características patriarcais da sociedade gaúcha, reforçadas pela influência positivista, trabalhava-se com a hipótese de que a família das jovens que ingressaram no Banco do Estado do Rio Grande do Sul teriam esboçado reação contrária ao trabalho destas, pelo fato do mesmo acontecer em um ambiente até então exclusivamente masculino.

O estudo dos depoimentos recolhidos, todavia, não indicou resistência dos familiares à escolha feita pelas jovens. Cinco das oito depoentes afirmaram que a família deu todo o apoio à sua decisão e que considerou uma ótima profissão. Algumas acrescentaram que os pais acharam que era um trabalho garantido, seguro e com bom salário. Outro argumento foi o de não haver a exigência de que a jovem fosse para outra cidade como ocorria com as professoras.

O último argumento acima citado, parece ter pesado, significativamente, para que as famílias aceitassem o trabalho das jovens no setor bancário. Uma das depoentes, que fizera o complementar (magistério), explicando a aceitação do pai, inclusive, afirmou: "Quando eu me formei (professora) eu fui nomeada para o interior e meu pai não me deixou ir".

Pelo que foi exposto, acredita-se que a atitude favorável da maioria dos pais quanto ao trabalho das filhas no banco foi, pelo menos em parte, motivada pela suposição de que estas não precisariam sair de suas cidades.

Ressalta-se, contudo, que legalmente qualquer trabalhadora admitida no Banco do Estado do Rio Grande do Sul poderia ser mandada para outra cidade, onde o banco tivesse sucursal ou agência. Apesar dessa possibilidade, não se tem registro de que, na prática, isso tivesse ocorrido. As transferências havidas, conforme pode ser constatado nas fichas das trabalhadoras, aconteceram por solicitação delas próprias.

Ainda com referência à aceitação do trabalho das jovens no banco, deve ser registrado o caso de uma trabalhadora que fez alusão a alguma resistência do pai ao seu trabalho, sendo dito que a mãe deu todo o apoio. O pai não desejava que a filha trabalhasse no banco, pois entendia que ela estaria "tirando o lugar de um homem" e que "ela tinha tudo em casa". A jovem acabou entrando escondida no banco e o pai só veio a saber algum tempo depois.

Essa situação é paradigmática: a filha queria trabalhar para ter independência financeira, mas precisou entrar no banco escondida do pai, que achava que ela estaria tirando o lugar de um homem. Essas afirmações retratam muito bem a época. As mulheres mais jovens, influenciadas pelas idéias novas, desejavam 
trabalhar, mas seu trabalho no espaço público era encarado pelos mais velhos, especialmente do sexo masculino, como desnecessário. Cabia aos homens, pais ou maridos, proverem a subsistência das mulheres da casa, que não deveriam "tirar" o espaço que era visto como, de direito, "pertencendo aos homens".

Retornando às entrevistas, cabe ainda um breve comentário a respeito da posição da mãe da depoente que, segundo esta, "deu toda a força" para que ela ingressasse no banco. Considera-se correto afirmar que as mulheres da geração de 1920, em geral, submetiam-se à vontade do marido e não trabalhavam fora de casa, mas estimulavam suas filhas a investir numa profissão, bem como a buscarem independência financeira. Alguns estudos, relativos ao período, já constataram isso.

\subsection{As relações entre homens e mulheres no banco}

Ao elaborar o projeto desta pesquisa, levantara-se a hipótese de que as relações de gênero estabelecidas no mundo do trabalho bancário, quando as primeiras mulheres ingressaram, deveriam ser bastante conflituosas. Imaginava-se que as mulheres que fizeram o primeiro concurso para ingresso no banco seriam mulheres com uma consciência crítica bastante desenvolvida, que procurariam conquistar uma posição dentro da instituição. Julgava-se que essas mulheres estariam rompendo com o padrão de dominação masculina estabelecido na sociedade gaúcha. Por outro lado, supunha-se que os homens resistiriam, vendo seu domínio ameaçado. Essa hipótese, no entanto, não se confirmou com as primeiras trabalhadoras do Banco do Estado do Rio Grande do Sul.

Todas as depoentes afirmaram que as relações entre homens e mulheres, no banco, eram as melhores possíveis, sendo marcadas por respeito, cordialidade e amizade. Algumas explicaram o bom relacionamento, fazendo referência à diferença de idade entre elas e a maioria dos homens. As mulheres tinham em torno de vinte ou vinte e poucos anos e grande parte dos homens, por volta de quarenta. Uma das depoentes acrescentou que os homens eram como pais delas, visto que eles eram "homens feitos e elas eram muito jovens".

Acredita-se que afirmações deste tipo caracterizam a natureza das relações estabelecidas entre homens e mulheres no espaço de trabalho bancário. Os homens eram vistos como pais das trabalhadoras e essas deveriam submeter-se à sua autoridade como, em uma sociedade patriarcal, as filhas submetem-se à "autoridade 
paterna”. Ao perceberem seus colegas como seus pais, evidentemente, as jovens bancárias não poderiam disputar com eles espaços de poder dentro do banco. Deveriam, isto sim, acomodar-se no lugar que lhes era destinado.

Apesar das repetidas referências a um ótimo relacionamento entre homens e mulheres, algumas afirmações causam certa perplexidade. Várias bancárias ouvidas disseram que tinham o hábito de andar sempre em grupo. "Saíamos juntas, entrávamos na mesma hora, todas juntas, se ia ao banheiro de duas, ... a gente se sentia assim meio insegura por aquela quantidade de colegas homens".

Outra questão a discutir é que quando se propôs às várias depoentes que falassem sobre as relações entre homens e mulheres, a maioria fez referência a que "os homens respeitavam as mulheres". Entende-se que isso sugere que a principal preocupação das mulheres era a de serem respeitadas como "diferentes dos homens" e não a de desfrutar de iguais condições no espaço de trabalho. As trabalhadoras ouvidas, portanto, não reivindicavam igualdade, mas serem tratadas pelos homens com respeito e deferência. Uma delas chegou a afirmar, com certo orgulho, que eram tratadas "como bibelôs".

Os documentos do banco relativos ao ingresso das mulheres, bem como as fichas funcionais, esclarecem que as jovens admitidas na instituição nos anos quarenta tiveram de se adaptar à posição que fora estabelecida para elas - pertenciam a um quadro separado dos demais funcionários do banco e seu cargo era denominado "auxiliar". Era o que estava estabelecido.

Nessa situação, as mulheres permaneceram por quase vinte anos, o que só se alterou a partir de 1961, quando deixaram de ser auxiliares, sendo incluídas como escriturárias no quadro de carreira geral do banco.

Não resta a menor dúvida de que essa questão regimental foi fator fundamental para manter as mulheres acomodadas às posições subalternas. Todavia, fatores de ordem cultural também foram relevantes para que as primeiras trabalhadoras do banco não se mobilizassem contra o que estava instituído. A mulher, na sociedade em geral, e na gaúcha, em especial, era socializada para ocupar uma posição secundária ou para ser auxiliar do homem. Portanto, o que estava instituído podia ser considerado, pelas próprias mulheres, como perfeitamente "natural" ou "normal".

Da parte dos homens, como as mulheres estavam enquadradas em uma posição inferior, não tinha porque entrar em conflito com elas. $\mathrm{O}$ regimento interno resguardava o lugar masculino. Isso 
explica por que as relações entre os trabalhadores de ambos os sexos foram amistosas, não se estabelecendo a disputa por posições, pelo menos nos primeiros vinte anos após o ingresso das primeiras trabalhadoras.

No que se refere ao relacionamento entre mulheres, quase todas as depoentes fizeram referência ao fato de que a convivência dentro da instituição as ligou profundamente. Três delas, inclusive, foram juntas ao Museu Banrisul para fazer seus depoimentos e afirmaram que sua amizade era de mais de cinqüenta anos.

Quase todas as depoentes referiram-se à Colônia de Férias do Banco ${ }^{2}$ como sendo um local que facilitava a aproximação entre os trabalhadores da instituição: "a gente ia muito para a Colônia de Férias"; "a gente se reunia lá todos os fins de semana, todo mundo andava junto, ia para o cinema à noite, para o Gioconda"; "a Colônia de Férias era uma coisa maravilhosa, ... tinha bailes e a gente dançava depois da janta, ... jogava sete e meio e ping-pong"; "lá iniciaram namoros que acabaram em casamento".

\subsection{A questão salarial e a possibilidade de ascensão no banco}

No que diz respeito à questão salarial, a primeira observação que pode ser feita é que as oito depoentes manifestaram satisfação com seus salários. Disseram que ganhavam bem, fizeram menção ao aumento que receberam já no segundo mês de trabalho e ainda afirmaram que recebiam mais de 12 salários por ano, porque havia as gratificações. Uma das depoentes chegou a dizer "a gente nem esperava aquele dinheirão todo que vinha e nós recebíamos num envelope azul".

Apesar de demonstrarem que estavam contentes com seus salários, quase todas as ouvidas fizeram referência a que, como elas faziam parte de quadro diferenciado do quadro geral do banco, havia diferenças de salário entre homens e mulheres.

Ficou muito claro, no material coletado, que a diferença salarial entre homens e mulheres era uma decorrência da maneira diferenciada que caracterizou a inserção das mulheres no banco, pelo menos no que se refere às primeiras trabalhadoras, pois elas estavam em um quadro à parte. Essa situação inviabilizou a ascen-

2 Conforme o Informativo Banrisul, a Colônia de Férias do BERGS foi construída em terreno adquirido pelo banco, em 1941, e ficava situada na Rua Mário Totta, na Tristeza. O terreno tinha 105 metros de frente para a rua e 102 de frente para o Rio Guaíba. 
são feminina e, como conseqüência, determinou que os salários das mulheres fossem inferiores aos dos homens.

\subsection{Trabalho no banco e obrigações domésticas}

Trabalhou-se nesta pesquisa com o pressuposto de que o fato de serem atribuídas às mulheres casadas todas as obrigações com os filhos, às quais se acrescentam também deveres com o marido e cuidados com a casa, dificulta a ascensão profissional das trabalhadoras em geral. Deve ser reconhecido que as próprias mulheres julgam-se as únicas responsáveis por essas tarefas e acabam considerando que a atividade profissional é secundária.

O estudo dos oito depoimentos recolhidos permitiu constatar que entre as três mulheres que obtiveram maior ascensão no banco, duas eram solteiras e não tinham filhos. Das que casaram, três deixaram o banco para dedicar-se à família e três permaneceram no banco. Saliente-se que destas, apenas uma obteve comissionamento, após 1961. Uma das que permaneceu no banco após o casamento e nascimento de três filhos relatou que não aceitou cargos porque desejava dedicar-se à família.

Essa forma de pensar pode ser explicada com base no que diz Chodorow (1990), ou seja, que as mulheres são educadas para a "maternagem". Como a obrigação de cuidar dos filhos é vista como exclusiva delas, enfrentam dificuldades para ascender profissionalmente. Acrescente-se que as mulheres aceitam e justificam como normal sua participação desigual no mundo do trabalho. Eficiente trabalho ideológico tornou a desigualdade no mundo do trabalho "natural" ou "normal," explicando-a como decorrentes das diferenças biológicas entre homens e mulheres.

A socialização a que são submetidas leva as mulheres a verem o trabalho assalariado como subordinado e complementar às obrigações com a família. Por essa razão, grande parte das mulheres procuram atividades em tempo parcial e que não exijam grande dedicação. Conforme Pena (1980, p. 15) é através da condição de esposa e de mãe que as mulheres se definem no mundo. Além disso, ainda segundo a mesma autora, "é jogada sobre seus ombros (a obrigação com) a saúde mental de seu núcleo familiar, sendo exigido que a mulher interiorize que seu papel natural é na família”. 


\subsection{Valores e atitudes das primeiras trabalhadoras do Banco do Estado do Rio Grande do Sul}

Constavam do roteiro de questões, que se propôs às bancárias ouvidas, algumas indagações que objetivavam analisar suas atitudes e seus valores e, na medida do possível, verificar se essas mulheres foram inovadoras, tendo rompido com os padrões de seu tempo e estabelecido novas visões de mundo e novos comportamentos, ou se mantinham os antigos valores e atitudes.

As questões propostas para atender a esse objetivo foram classificadas em seis categorias: 1. Questões relativas ao gosto e a participação política; 2. Questões relativas à sindicalização, participação no sindicato e nas greves; 3 . Questões relativas à educação de meninos e meninas; 4 . Questões relativas à escolha das profissões por homens e mulheres; 5 . Posição frente às mudanças do mundo; 6. Avaliação da vida da mulher ontem e hoje.

Colhidos os depoimentos, foi possível constatar que a ampla maioria das depoentes não gostava de política, quase não a acompanhava, votava obrigatoriamente e, no máximo, informavase sobre o assunto. Apenas uma das ouvidas afirmou gostar de política, acompanhar e discutir sempre.

Com relação à participação sindical, constatou-se o seguinte: quatro das depoentes declararam que eram sindicalizadas e uma não tinha certeza se era ou não, mas a maioria declarou que não participava do sindicato a não ser em festinhas e, também, que não participava das greves. Em dois dos casos, a depoente disse ter participado de uma greve, mas em um deles a trabalhadora sentiuse meio traída pelos colegas que a fizeram participar. No outro caso, a participação parece ter sido atribuída a "uma certa irresponsabilidade do grupo". Somente no oitavo depoimento tem-se uma posição diferente da posição generalizada do grupo, visto que a resposta é que "era sindicalizada e participava ativamente das greves".

Esse conjunto de respostas é indicativo de que as trabalhadoras ouvidas não eram mulheres muito politizadas. Suas respostas sugerem que elas podem ser incluídas no conjunto das mulheres que consideram que a política e o sindicato são "coisas de homens".

No que se refere à educação e profissão é interessante verificar que a maioria das ouvidas considera que homens e mulheres devem ser educados de forma diferente e que existem profissões somente para homens e profissões próprias para as mulheres. 
Essas respostas podem parecer paradoxais quando se está tratando com algumas das primeiras mulheres que ingressaram num setor de trabalho que até então era exclusivamente masculino. Todavia, se levarmos em consideração que tais mulheres ingressaram em num mundo de trabalho masculino (o BANRISUL), mas que lá ficaram "no seu lugar," como auxiliares, em um quadro à parte, durante quase vinte anos, o que foi dito torna-se mais compreensível. As respostas obtidas nesta parte autorizam-nos a afirmar que as primeiras mulheres que ingressaram no Banco do Estado do Rio Grande do Sul, ao menos as ouvidas, apesar de terem optado por um setor até então exclusivamente masculino, não eram inovadoras ou progressistas.

As duas últimas categorias de respostas indicam que as mulheres ouvidas consideram que houve muitas mudanças no mundo e se dividem, avaliando-as positiva ou negativamente. A ampla maioria considera que a vida das mulheres é muito melhor na atualidade. Tais melhorias estão associadas a ter mais liberdade, mais oportunidade de emprego, enfim ter seu próprio dinheiro, e até possuir uma série de facilidades em casa.

Essas respostas podem sugerir que as mulheres ouvidas têm certas atitudes progressistas, já que consideram importante ter mais oportunidade de emprego, ter o seu dinheiro e, principalmente, quando avaliam positivamente a maior liberdade das mulheres. Nesse tipo de resposta, também está contida uma crítica a sua época, quando era difícil para as mulheres terem emprego, dinheiro próprio e liberdade.

\section{Considerações finais}

O estudo realizado permitiu que se percebesse que as depoentes olharam do seu presente para o passado, confirmando o que coloca Halbwachs (1925). Todas elas eram mulheres de mais de setenta anos que evidenciaram uma certa nostalgia do tempo em que eram jovens e cheias de esperanças. Não resta a menor dúvida de que "aquele tempo do banco" foi reconstituído, pois, como afirma Bosi (1994), lembrar não é reviver, mas refazer, reconstruir, repensar, com imagens e idéias de hoje, as experiências do passado.

De qualquer forma, a contribuição dos relatos feitos para a reconstituição da identidade do grupo foi de fundamental importância permitindo que se chegasse a algumas conclusões relevantes: 
Em primeiro lugar, foi possível ter bem claro que a entrada das mulheres no Banco do Estado do Rio Grande do Sul esteve associada ao confronto mundial de 1939-45, embora não tenha sido, propriamente, a falta de funcionários homens que tenha levado o banco a decidir-se a admitir mulheres. Pesou significativamente nessa decisão a preocupação em evitar a admissão de homens, que poderiam ser convocados para o Serviço Militar, a qualquer momento, ficando o banco obrigado a continuar pagando os encargos desse funcionário. Ressalte-se que esse foi o procedimento da maioria das empresas da época.

Em segundo lugar, foi possível perceber que a direção do banco foi bastante cautelosa quando decidiu aceitar mulheres na instituição, tomando várias precauções. Foi emitida a Resolução n ${ }^{\circ}$ 406, na qual ficavam definidos todos os detalhes relativos ao ingresso das mulheres, com o objetivo de evitar que a decisão tomada viesse a ocasionar problemas futuros.

Em terceiro lugar, o estudo permitiu reconstituir a identidade das primeiras trabalhadoras do banco (jovens, solteiras, de classe média, com grau de instrução médio), bem como perceber que, como uma boa parte das jovens do início da década de quarenta, estavam desejosas de trabalhar, o que se articulava com a conjuntura política vivida, a qual incentivava o trabalho feminino. Porém, também ficou evidente que as mulheres que entraram no banco entre 1943-45 estavam ainda muito marcadas pelas características da sociedade gaúcha, onde o positivismo exercera papel significativo. Isso levou algumas a trabalhar somente até casarem ou, no caso das casadas que permaneceram trabalhando, a colocar sempre as obrigações familiares à frente das obrigações profissionais.

Em quarto lugar, ficou claro que as primeiras bancárias tiveram limitadas possibilidades de ascender no banco, até meados da década de sessenta, devido à regulamentação interna da instituição. Por essa razão, em geral, ganhavam bem menos que os homens.

Em quinto lugar, também ficou evidente que a maioria das mulheres considerava natural ocupar posições subalternas no banco e que não estavam preocupadas em exigir igualdade de condições com os homens. O que as mulheres desejavam era, como diferentes destes, serem respeitadas e bem tratadas por eles.

Em sexto lugar, é possível afirmar que as relações de gênero, no Banco do Estado do Rio Grande do Sul, nas décadas de quarenta, cinqüenta, em geral, não foram marcadas pela disputa de poder entre homens e mulheres, visto que estas se acomodaram à posição que lhes foi destinada. 
Finalmente, por tudo que foi constatado, pode se dizer, que, diferentemente do que se esperava, essas mulheres que foram pioneiras no ingresso no Banco do Estado do Rio Grande do Sul não eram muito politizadas (não gostavam de política, não atuavam no sindicato), ou seja, ainda apresentavam fortes marcas da sociedade patriarcal gaúcha.

\section{Referências}

BERGSON, Henri. Matéria e memória. 2. ed. São Paulo: Martins Fontes, 1999.

BOSI, Ecléa. Memória e sociedade: lembranças de velhos. 3. ed. São Paulo: Cia. das Letras, 1994.

CHODOROW, Nancy. Psicanálise da maternidade: uma crítica a Freud a partir da mulher. Rio de Janeiro: Rosa dos Tempos, 1990.

DUBY, Georges; PERROT, Michelle (Orgs.). História das mulheres no Ocidente. Vol. 1: A Antiguidade. Porto: Edições Afrontamento, 1990.

HALBWACHS, Maurice. Les cadres sociaux de la mémoire. Paris: Presses Universitaires de France, 1925.

La mémoire collective. Paris: Presses Universitaires de France, 1950.

HELLER, Agnes. Uma teoria da História. Rio de Janeiro: Civilização Brasileira, 1993.

NORA, Pierre. Memória colectiva. In: LE GOFF, Jacques; CHARTIER, Roger; REVEL, Jacques (Orgs.). A história nova. Coimbra: Almedina, 1990.

PENA, Maria Valéria Junho Pena. A mulher na força de trabalho. In: BIB, Rio de Janeiro, v. 9, 1980, p. 11-22.

PERROT, Michelle. Os excluídos: operários, mulheres e prisioneiros. Rio de Janeiro: Paz e Terra, 1992.

SANTOS, Myrian S. dos. Sobre a autonomia das novas identidades coletivas: alguns problemas teóricos. Revista Brasileira de Ciências Sociais, São Paulo, Anpocs, v. 13, n. 38, 1998.

THOMPSON, Paul. A voz do passado - História Oral. Rio de Janeiro: Paz e Terra, 1992. 